\title{
ISOLAMENTOS BACTERIANOS DE FETOS ABORTADOS BOVINOS EXAMINADOS NO INSTITUTO BIOLÓGICO DE SÃO PAULO, NO PERÍODO DE 1985 A 1992
}

\author{
BACTERIAL ISOLATIONS FROM BOVINE ABORTED FETUSES EXAMINED IN INSTITUTO \\ BIOLÓGICO OF SÃO PAULO STATE, BRAZIL, FROM 1985 TO 1992
}

\author{
Margareth Ellde GENOVEZ'; Ellana SCARCELLI'; Sandra ROJAS'; Waldyr GIORGI'; Carlos Noryukl KANETO'
}

\section{RESUMO}

\begin{abstract}
No período de 1985 a 1992, foram analisadas bacteriologicamente 544 amostras de órgãos e anexos fetais, provenientes de 282 fetos bovinos, oriundos de rebanhos, na maioria leiteiros, procedentes de vários estados do Brasil. Foram consideradas como possíveis causas de abortamento, as bactérias patogênicas e as culturas puras ou preponderantes de bactérias oportunistas. Excluindose os materiais impróprios para exame (25/282), dos 257 restantes, em 37,4\% foram diagnosticadas causas bacterianas, tais como: Brucella abortus (6,2\%), Leptospira spp (6,2\%), Staphylococcus aureus $(5,4 \%)$, Campylobacter fetus $(4,7 \%)$ e Streptococcus Beta hemolítico $(3,5 \%)$. Os focos destes agentes apresentavam-se amplamente distribuidos no Estado de São Paulo.
\end{abstract}

UNITERMOS: Aborto, bovinos; Diagnóstico bacteriológico

\section{INTRODUÇĀO}

A investigação laboratorial das causas de abortamento nos animais de produção deve ser incentivada, principalmente em países onde a pecuária assume papel de destaque na economia.

No Brasil, os dados obtidos pelos laboratórios responsáveis pelo diagnóstico de abortamentos têm sido pouco divulgados $^{3,6.7}$, o que dificulta qualquer estimativa de prejuizos ou ação de controle e prevenção no sentido mais amplo.

O presente estudo tem por objetivo a análise dos resultados dos exames bacteriológicos de fetos bovinos encaminhados para a Seção de Doenças de Bovinos, Ovinos e Caprinos do Instituto Biológico de Săo Paulo, no período de 1985 a 1992.

\section{MATERIAL E MÉTODO}

Os materiais examinados foram 544 amostras de órgãos e anexos, provenientes de 282 fetos bovinos (Quad. 1) oriundos de rebanhos, na maioria leiteiros $(90,8 \%)$, procedentes de diversas cidades dos Estados de São Paulo (Amparo, Araçatuba, Araçoiaba da Serra, Arandu, Atibaia, Artur Nogueira, Assis, Avaré, Bariri, Batatais, Bernardino de Campos, Buri, Caçapava, Cajurú, Campinas, Campos do Jordåo, Castelo Campinas, Colina, Cravinhos, Cruzeiro, Descalvado, Eldorado, Fartura, Fernandópolis, Guararapes, Guararema, Holambra, Icém, Igarapava, ljuí, Indaiatuba, Iperó, Ipeúna, Itaí, Itapetininga, Itatiba, Itú, Itupeva, Jaboticabal, Jacareí, Jacupiranga, Jacutinga, Jaguari, Jaguariúna, Jardinópolis, Jarinú, Juquitiba, Lins, Lorena, Marabá, Marilia, Mairiporă, Martinópolis, Mogi das Cruzes, Morungaba, Mucutinga do Sul, Nova Odessa, Ocauçú, Oscar Bressane, Ourinhos, Paraibuna, Pederneiras, Pedra Bela, Pereiras, Piedade, Pilar do Sul, Pindamonhangaba, Piracicaba, Pirajuí, Pirapozinho,
Pitangueiras, Potirendaba, Reginópolis, Ribeirão Preto, Santa Branca, Santa Rita do Passa Quatro, Santo Antônio da Posse, Santa Isabel, São João da Boa Vista, São José dos Campos, São José do Rio Pardo, São José do Rio Preto, São Paulo, São Pedro, São Simāo, São Roque, Sarapuí, Savena, Sertāozinto, Sorocaba, Tapiritiba, Tatuí, Tietê, Tremembé, Vargem Grande do Sul, Vera Cruz, Vinhedo e Votuporanga); Minas Gerais (Bicas, Campanha, Extrema, Muzambinho, Sacramento, Santa Rita do Sapucaí, Três Coraçōes e Varginha); Paraná (Carambeí, Castro e Santo Inácio); Mato Grosso do Sul (Bataguaçu); Rio de Janeiro (Piraí) e Rio Grande do Sul (Passo Fundo). Dentre as propriedades trabalhadas, $25 \%$ utilizavam exclusivamente serviço de monta natural, $37 \%$ somente inseminação artificial e $40 \%$ alternavam ambos os métodos. A freqüência mensal dos materiais é descrita no Quad. 2.

As informaçðes clínicas e/ou zootécnicas foram obtidas através do preenchimento de fichas onde constavam os seguintes itens: localidade, raça, período gestacional, tipo de manejo incluindo número de animais do rebanho e de acometidos. vacinas, sintomas clínicos, dados de necrópsia e diagnóstico provável. No caso do preenchimento incompleto da ficha informativa, a idade fetal foi estimada por estudo anatômico.

$$
\text { QUADRO } 1
$$

Relação $\theta$ freqüéncia de órgāos $\theta$ anexos felais bovinos recebidos para exame na Seção de Doenças de Bovinos, Ovinos e Caprinos do Instituto Biológico de São Paulo, no período de 1985 a 1992.

\begin{tabular}{lr}
\hline Materiais & Freq \\
\hline Estômago (conteúdo gástrico) & 233 \\
Aim & 143 \\
Figado & 83 \\
Placenta & 08 \\
Outros & 06 \\
\hline Total & 473
\end{tabular}

Obs : Impróprios para exame: 23 fetos e 02 placentas. 
QUADRO 2

Freqüéncia mensal de letos bovinos recebidos para exame na Seção de Doenças de Bovinos, Ovinos a Caprinos do Instituto Biológico de Sào Paulo, no periodo de 1985 a 1992.

\begin{tabular}{cccccccccccccc}
$\begin{array}{c}\text { Mès } \\
\text { Ano }\end{array}$ & J & F & M & A & M & J & J & A & S & O & N & D & Total \\
\hline 85 & 1 & - & 3 & 3 & - & 1 & 2 & 1 & 3 & 3 & - & 1 & 18 \\
86 & 3 & 1 & 3 & 5 & 3 & 3 & 4 & 5 & 2 & 2 & 4 & 7 & 42 \\
87 & 3 & 3 & 8 & 6 & 4 & 4 & 7 & 5 & 1 & 5 & 3 & 4 & 53 \\
88 & - & & - & - & - & 8 & 5 & 3 & 3 & - & 5 & 3 & 22 \\
89 & 3 & 4 & 1 & 6 & 1 & 3 & 3 & 3 & 5 & 3 & 2 & 3 & 35 \\
90 & 1 & 1 & 1 & 6 & 4 & 5 & 2 & 5 & 2 & 1 & 6 & 2 & 36 \\
91 & 4 & 4 & 5 & 2 & 2 & 2 & 4 & 7 & 1 & 3 & - & & 34 \\
92 & 4 & 10 & 5 & 5 & 3 & 3 & 2 & 3 & 5 & & & & 40 \\
\hline Total & 19 & 23 & 26 & 33 & 17 & 29 & 29 & 32 & 22 & 17 & 15 & 20 & 282 \\
\hline
\end{tabular}

O processamento bacteriológico constituiu-se de:

1. As amosuras do conteúdo gásurico foram subdivididas $\mathrm{cm}$ alíquotas, assim cultivadas 6 :

a. em ágar Brucella (Difco) acrescido de $10 \%$ de sanguc de carnciro com e sem adição de mistura antibiótica (polimixina B - $10.000 \mathrm{UI} / \mathrm{l}$, bacitracina - 15.000 UI/I, novobiocina - 0,005 g/l e cicloheximida - $0,02 \mathrm{~g} / \mathrm{l})$, incubadas cm atmosfera de $95 \% \mathrm{~N}_{2}+5 \% \mathrm{CO}_{2}+\mathrm{O}_{2}$ residual, a $37^{\circ} \mathrm{C}$ por até 7 dias;

b. em ágar Brucella (Difco) acrescido de $10 \%$ de sangue de carneiro e cm ágar EMB - Levine (Difco), incubadas $\mathrm{cm}$ acrobiose a $37^{\circ} \mathrm{C}$ por 48 horas;

c. em meio de Fletcher (Difco) acrescido de $10 \%$ de soro inativado de coclho, incubado $\mathrm{em}$ acrobiose a $30^{\circ} \mathrm{C}$ por até 30 dias.

2. Os fragmentos de rins elou fígados foram macerados e seguiram o mesmo processo descrito $\mathrm{cm}$ 1.c.

3. Os fragmentos de placenta foram processados como descrito $\mathrm{cm} / \mathrm{e} 2$.

As culturas foram identificadas pelos métodos usuais ${ }^{\natural}$ conforme 0 agente suspeito.

Decalques de rim e/ou fígado foram submetidos à técnica de imunofluorescência indireta para diagnóstico da leptospirose.

Foram consideradas como possiveis causas de abortamento as bactérias potencialmente patogênicas e as culturas puras ou preponderantes de bactérias potencialmente patogênicas ou oportunistas. No caso da leptospirose foram considerados positivos os isolamentos c/ou a deteç̧åo de leptospiras pela rcação de imunofluorescência indireta.

\section{RESULTADOS}

Excluindo-se 25 fetos impróprios para exame, os 257 restantes uiveram Brucella abortus e Leptospira spp como os agentes bacterianos mais frequientes (16/257), seguidos por Staphylococcus aureus (14/257) e Campylobacter fetus (12/ 257), como se observa na Tab. 1. A distribuiçăo mensal de resultados positivos para agentes bacterianos e possíveis causadores de abortamentos em bovinos, no período de 1985 a
1992 encontra-se descrita na Tab. 2. Pela análise destas tabelas verifica-se que $37,4 \%$ (96/257) das causas de abortamento bovino foram de origem bacteriana, sendo os meses de julho a setcmbro os de maior ocorrència considerando-se praticamente o mesmo número de felos examinados mensalmente (Quad. 2).

Houve predominância de abortamentos entre $7^{\circ} 8^{\circ}$ mês de gestaçåo $(37,2 \%)$ sendo que nos fetos onde diagnosticou-se leptospirose o periodo gestacional médio foi de 6 meses, para brucelose 7,5 meses, para campilobacteriose por Campylobacter retus subsp venerealis 4 meses e por Campylobacter fetus subsp fetus 6 meses. Entre os agentes opertunistas Staphylecoccus aureus provocou abortamentos no periodo gestacional médio de 7 meses e Streptoroceus Bela hemolítico 6,3 meses.

A procedencia desses rebanhos com problemas reprodutivos c os respectivos agentes isolados sao apresentados na Tab. $3 \mathrm{c}$ na Fig. 1.

TABELA 1

Frequiencia e porcentagem de isolamentos de bactérias em órgáos $\theta$ anexos fetais bovinos examinados pela Seçāo de Doenças de Bovi nos. Ovinos e Caprinos do Instituto Biológico de São Paulo, no periodo de 1985 a 1992, segundo a natureza do microrganismo identificado

\begin{tabular}{lcc}
\hline Bactéria isolada & Frea & $\%$ \\
\hline Brucella sbortus & 16 & 6.2 \\
Leptospira sp & 16 & 6.2 \\
Staphylococcus aurous & 14 & 5.4 \\
Campylobacter felus subsp. fetus & 04 & 1,6 \\
Campylobacter felus subsp venerealls & 08 & 3.1 \\
Campylobacter cryaerophila & 03 & 1.2 \\
Streptococcus Beta hemolitico & 09 & 3.5 \\
Escherichla coll Beta hemolitica & 04 & 1.6 \\
Streptococcus spp (grupo D) & 01 & 0.4 \\
Streptococcus spp & 04 & 1.6 \\
Salmonella dublin & 03 & 1.2 \\
Corynebacterium pyogenes & 02 & 0.8 \\
Corynebacterium striatum & 01 & 0.4 \\
Streptococcus Beta hemol + E. coll Beta hemol. & 01 & 0.4 \\
Staphylococcus aureus + Leptospira sp & 01 & 0.4 \\
Pseudomonas aeruginosa & 01 & 0.4 \\
\hline Sub-Total Positivo & 96 & 37.4 \\
\hline Outras causas & 161 & 62.6 \\
\hline Total & 257 & 100 \\
\hline
\end{tabular}

\section{TABELA 2}

Frequeència de felos bovinos examinados pela Seçăo de Doenças de Bovinos, Ovinos e Caprinos do Instituto Biológico de Sáo Paulo, no periodo de 1985 a 1992, em que houve isolamento de bactérias segundo o ano e o més de processamento. A

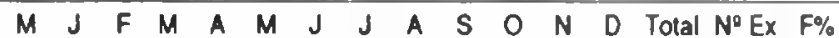

\begin{tabular}{llllllllllllllll}
\hline 85 & - & - & 1 & - & - & - & - & - & 3 & - & - & - & 04 & 17 & 23,5 \\
86 & 2 & - & 1 & 2 & 1 & 1 & 2 & 1 & 1 & - & 3 & 5 & 19 & 38 & 50,0 \\
87 & 2 & 1 & 3 & 3 & 2 & 2 & 6 & 3 & 1 & - & 2 & 2 & 27 & 49 & 55,1 \\
88 & - & - & - & - & - & 2 & 1 & 2 & 1 & - & - & - & 06 & 20 & 30,0 \\
89 & - & 2 & - & - & 1 & - & 2 & - & 1 & - & - & - & 06 & 32 & 18,8 \\
90 & - & - & - & 1 & 1 & 1 & - & 1 & 2 & - & - & - & 06 & 33 & 18,2 \\
91 & 1 & 2 & 2 & 1 & 1 & 1 & 4 & 4 & - & - & - & - & 16 & 33 & 48,5 \\
92 & 1 & 2 & 2 & 1 & 1 & 1 & 1 & 3 & - & - & - & - & 12 & 35 & 34,3 \\
\hline Total & 6 & 7 & 9 & 8 & 7 & 8 & 16 & 14 & 9 & 0 & 5 & 7 & 96 & 257 & 100
\end{tabular}


GENOVEZ, M.E.; SCARCELU, E.; ROJAS, S.; GIORGI, W.; KANETO, C.N. Isolamentos baclerianos de fetos aborudos bovinos examinados no Instituto Biológico de Sĩo Paulo, no periodo de 1985 a 1992. Braz. J. vet. Res. anim. Sd., Siro Paulo, v. 30, n. 2, p. 107-12, 1993.

TABELA 3

Resultados de exames bacteriológicos de felos bovinos, realizados no Instituto Biológico de Sáo Paulo, provenientes de seis Estados, no periodo de 1985 a 1992, segundo o Estado e Municipio de origem e a caracterizaçăo do microrganismo isolado.

\begin{tabular}{|c|c|c|}
\hline Estado & Cidade & Agente \\
\hline \multirow[t]{12}{*}{ SP } & $\begin{array}{l}\text { Araçatuba } \\
\text { Caçapava } \\
\text { Campinas (2) } \\
\text { Descalvado (2) } \\
\text { Jacupiranga } \\
\text { Marabá Paulista } \\
\text { Marllia } \\
\text { Paraibuna } \\
\text { Pindamonhangaba } \\
\text { Piracicaba } \\
\text { Sáo José dos Campos } \\
\text { Vera Cruz }\end{array}$ & Brucella abortus \\
\hline & $\begin{array}{l}\text { Baniri } \\
\text { Bragança Paulista } \\
\text { Campinas (3) } \\
\text { lguapó } \\
\text { Jacarel (2) } \\
\text { Pindamonhangaba } \\
\text { Samta Branca } \\
\text { São José dos Campos } \\
\text { Săo José do Rio Preto } \\
\text { Tielé }\end{array}$ & Leptospira sp \\
\hline & $\begin{array}{l}\text { Avaŕ́ } \\
\text { Braganca Paulista (4) } \\
\text { Guararema } \\
\text { perd } \\
\text { hatba } \\
\text { Piodade } \\
\text { Santa Branca (3) }\end{array}$ & Staphylococcus aureus \\
\hline & $\begin{array}{l}\text { Buri } \\
\text { Jacarel (2) } \\
\text { Jaguariuna }\end{array}$ & Campylabecter folus subsp. folus \\
\hline & $\begin{array}{l}\text { Cajurú } \\
\text { Campinas } \\
\text { Guararema } \\
\text { Jacupiranga } \\
\text { Marllia } \\
\text { Sama Isabel } \\
\text { Tremembe }\end{array}$ & Campytobacter fetus subsp venerealis \\
\hline & Såo Paulo & Campylobacter cryaerophila \\
\hline & $\begin{array}{l}\text { Bragança Paulista } \\
\text { Jacarel } \\
\text { Marabá Paulista (3) } \\
\text { Muculinga do Sul } \\
\text { Ocaugu } \\
\text { Oscar Bressane } \\
\text { Sao Roque }\end{array}$ & Streptococcus Beta hemol. \\
\hline & $\begin{array}{l}\text { Bragança Paulista } \\
\text { Cruzeiro } \\
\text { Jacarel }\end{array}$ & Escherichia coli hemol. \\
\hline & $\begin{array}{l}\text { Avaré } \\
\text { Jacarel } \\
\text { Nova Odessa } \\
\text { Ocaugu }\end{array}$ & Streptococcus spp \\
\hline & $\begin{array}{l}\text { Campinas } \\
\text { Indaiatuba } \\
\text { lpeína } \\
\text { Marllia }\end{array}$ & Staphylococaus spp \\
\hline & $\begin{array}{l}\text { Caçapava } \\
\text { Marilia }\end{array}$ & Conynebacterium pyogenes \\
\hline & Jacarel & Corynebacterium strialum \\
\hline
\end{tabular}

Continua
Continuaçáo

TABELA 3

Resultados de exames bacteriológicos de letos bovinos, realizados no instituto Biológico de Sáo Paulo, provenientes de seis Estados. no periodo de 1985 a 1992, segundo o Estado e Municipio de origem e a caracterizaçăo do microrganismo isolado.

\begin{tabular}{|c|c|c|}
\hline Estado & Cidado & Agente \\
\hline & $\begin{array}{l}\text { Lorena } \\
\text { Sertáazinho } \\
\text { Sta. Rita do P. Quatro }\end{array}$ & Escherichia coli \\
\hline & Jacarel & Pseudomonas aeruginosa \\
\hline & $\begin{array}{l}\text { Assis } \\
\text { Pindamonhangaba }\end{array}$ & Salmonella dublin \\
\hline & Campinas & Streptococcus Beta hemol $+E$. coth hemo \\
\hline & $\begin{array}{l}\text { Pindamonhangaba } \\
\text { Santa Branca }\end{array}$ & Staphylococcus spp + Leptospira sp \\
\hline \multirow[t]{4}{*}{ MG } & Bicas & Leplospira sp \\
\hline & Campanha & Escherichila coll hemol. \\
\hline & $\begin{array}{l}\text { Extrema } \\
\text { Varginha }\end{array}$ & Slaphylococcus aureus \\
\hline & Sta Rita do Sapucal & Escherichis coli \\
\hline RJ & Piral & Campylobacter felus subsp. venereaks \\
\hline \multirow[t]{2}{*}{ PR } & $\begin{array}{l}\text { Carambei } \\
\text { Castro }\end{array}$ & Campylobacter cryaerophila \\
\hline & Castro & Salmonella dubln \\
\hline RS & Passo Fundo & Brucalla abortus \\
\hline MS & Bataguaçu & Brucella abortus \\
\hline
\end{tabular}

SP=S̄oo Paulo; MG=Minas Gerais; $R=$ Rio de Janeiro; PR=Parańá; RS=Rio Grande do Sul: MS=Mato Grosso do Sul.

( ) =Número de isolamentos por Munićpio.

\section{DISCUSSĀO}

Neste cstudo, $37,4 \%$ dos aboramentos acusaram a presença de agentes bacterianos. Como apenas as causas bacterianas foram investigadas, outros agentes ${ }^{11,15}$ de natureza viral, micótica ou parasitária, distúrbios fisiológicos, genéticos ou mesmo de origem traumática poderiam ser os responsáveis pelos restantes $62,6 \%$. De qualquer forma, a participação de bactérias como agente abortivo pode ser considerada elevada. No estudo de KIRKBRIDE et al. ${ }^{12}$, 1973, de 2544 casos de aboramento bovino, $24,2 \%$ relacionavam-se com agentes bacterianos, enquanto HUBBERT et al.', 1973, demonstraram que em 3812 amostras fetais, $14,6 \%$ dos abontos eram de origem bacteriana.

Apesar da grande variedade de gêneros e espécies bacterianas detectados como etiologia de abortamento, os resultados apresentados mostraram que as divergências entre os autores ${ }^{9.10,12,115}$ ocorreram apenas nas respectivas frequiências, enquanto os países que conseguiram manter a brucelose bovina em níveis inferiores a 1\%9.12, apresentaram os gêneros Corynebacterium, Staphylococcus e Streptococcus como os mais prevalentes dos casos de abortamentos bacterianos.

No presente trabalho, destacaram-se os classicamente conhecidos como agentes abortivos: Brucella, Leptospira e Campylobacter. No caso específico da brucelose, quatro dos 16 isolamentos foram oriundos de fêmeas receptoras de embriðes de alta linhagem genética, dai fazer-se um alerta para que os cuidados destinados às doadoras sejam também extendidos às receptoras. 
Outro aspecto que merece consideração é a comprovação da existência de focos de brucelose bovina por todo Estado de São Paulo, tornando-se imprescindivel a melhoria na atuaçăo sanitária dos órgãos competentes.

Com relação à leptospirose, também observou-se uma maior freqüência de isolamentos $(6,2 \%)$ que os outros autores ${ }^{9.12}$ ( 1,8 e $2,5 \%$, respectivamente). Este fato esteve sempre associado ao mau acondicionamento e estocagem da raçăo e seus constituintes, principalmente milho, promovendo enorme afluxo de roedores e ainda, por destinação inadequada de excretas e águas servidas. Como agravante, observou-se a prática que vem se difundindo entre os criadores, que é a utilização de vacinação sistemática como forma exclusiva de tratamento curativo, não associada à antibioticoterapia, a qual teria o papel fundamental da eliminação do estado de portador renal pela maioria dos sorotipos infectantes ${ }^{14}$.

Dos 12 isolamentos de bactérias do gênero Campylubacter, $50 \%$ foram provenientes da bacia lcitcira do Vale do Paraíba, Estado de Săo Paulo. Uma grande parte desses criadores referiram que com o intuito de aumentar as taxas de nascimentos se utilizavam do empréstimo de touros entre propriedades vizinhas e ainda associavam o emprego de monta natural alternada à inseminação artificial. Como essas práticas cram realizadas sem qualquer tipo de controle sanitário, na verdade o que ocorria era a intensa disseminação de agentes de comportamento venéreo, como Campylobacter,"s.

Os três isolamentos de Campylobacter (Archobacter) cryaerophila, foram obtidos a parur do conteúdo gástrico sem associação com outros agentes patogênicos bactcrianos.

Alêm de fetos abortados, essa espécie bacteriana também tem sido verificada em amostras de fezes de bovinos e suínos e de leite de vacas com mastite. Porém, a falta de demonstraçăo de patogenicidade por infecção experimental não tem permitido incriminá-la como agente eciológico de abortamento ${ }^{13.16}$.

Outro ponto a se destacar é a elevada frequiência de abortamentos causados por Staphylococcus aureus $(5,4 \%)$, a qual poderia indicar uma inter-relaçăo com a presença de mastite por esse agente $^{1}$, sem dúvida o mais prevalente. Ao contrário do que ocorre no abortamento devido à mamite por $\mathbf{E}$. coli ${ }^{2}$, onde há liberaçăo de endotoxinas capazes de desencadearem intensa rcação inflamatória mediada principalmente por prostaglandinas com conseqüente regressāo do corpo lúteo; o abortamento por Staphylococcus aureus poderia indicar essa inter-relaçæo por mecanismos ainda não totalmente esclarecidos².

Observando-se os períodos gestacionais médios dos abortamentos e seus respectivos agentes bacterianos, verificou-se haver sobreposição entre eles, não permitindo em nenhum momento a instituiçăo de hipótese diagnóstica baseada apenas nesses dados portanto, sendo necessário,- o diagnóstico diferencial revelado pelos exames laboratoriais.

Embora citada por alguns autores ${ }^{9,10,12}$, não foi observada sazonalidade na ocorrência dos microrganismos isolados dos fetos abortados; contudo, detectou-se aumento absoluto, estatisticamente não significativo, na frequiência de abortamentos por causas bacterianas no periodo de julho a setembro $\left(x^{2}\right.$ obs. para julho $=0,138 ; x^{2}$ obs. para agosto $=0,041 ; x^{2}$ obs. para setembro $=0,064$, onde $x^{2}$ crítico $=3,84$ para $p<0,05$ ).

Por fim, faz-se um alerta aos profissionais veterinários para que atentem para o papel do diagnóstico laboratorial nas enfermidades reprodutivas e que estes estabeleçam uma conduta metódica, sistemática e em harmonia com os laboratórios de diagnóstico, remetendo materiais adequados e em boas condiçðes. E mais, para que se conscientizem da importância de se conhecer as causas regionais dos problemas e suas possiveis associaçðes criatórias específicas, condiçðes fundamentais para a viabilização de qualquer programa sanitário de controle e erradicaçào de enfermidades.

\section{SUMMARY}

During 1985-1992, 544 samples of fetal organs and anexus, including stomach contents, were bacteriologicaly examined. These specimens came from dairy herds, from several states of Brazil. Pathogenic bacteria and pure culture or predominant opportunist organisms, were the basis for diagnosis of abortifacient individual agents. From 257 fetuses, excluding the unsuitable ones, $37,4 \%$ were associated to bacterial causes, such as: Brucella abortus $(6,2 \%)$, Leptospira sp $(6,2 \%)$, Staphylococcus aureus $(5,4 \%)$, Campylobacter fetus $(4,7 \%)$. Streptococcus Beta hemolytic $(3,5 \%)$. These microorganisms have presented largely spread in several cities of São Paulo State, Brazil.

UNITERMOS: Abortion in Cattle; Bacteriological diagnosis

\section{REFERENCIAS BIBLIOGRÁFICAS}

01-COSTA, E.O.; COUTINHO, S.D.; CASTILHO, W.; TEIXEIRA. C.M. Etiologia bacteriana da mastite bovina no Estado de São Paulo, Brasil. Rev. Microblol., v.17, p.107-12, 1986.

02-CULLOR, J.S. Mastitis in dairy cows: does it hinder reproductive performance? Vet. Med., v.86, p.830-5, 1991.

03-DÁPICE, M. Ocorrência de aborlo bovino no Estado de Săo Paulo devido ao Vibrio felus. O Blológico, v.22, p.15-8, 1956.

04-GENOVE\%, M.E.; SCARCELLI, E.; PICONE, A.B.B. Avaliação de dois métodos de coleta de muco prepucial no diagnóstico da campilobacteriose genital em touros. O Biokgico, v.52, p.7$11,1986$.

05-GENOVEZ, M.E.; SCARCELLI, E.; ROJAS. S. Campilobacteriose genital: proposta de diagnóstico mais sensivel em touros. Arq. Inst. Biol., v.56, p.5-7, 1989.

06-GIORGI, W.; GENOVEZ, M.E.; SCARCELLI, E.; PICONE, A.B.B. Infertilidade e abortamentos em rebanho bovino causados por Campylobacter fetus subsp fetus: profilaxia e tratamento. Rev. Microblol., v.17, p.342-5, 1986.

07-GIORGI. W.; LOBẢO, A.O.; SANTAROSA, C.A.; FRANÇA. E. Abortamentos em bovinos: isolamento de Salmonella dublin. Arq. Inst. Biol., v.35, p.185-8, 1968.

08-HOLT, J.C.; KRILG, N.R. Bergey's manual of systematic bacteriology. Baltimore, Williams \& Wilkins, 1984.

09-HUBBERT, W.T.; BOOTH, G.D.; BOLTON, W.D.; DUNNE, H.W. Bovine abortion in five Northeastem States, 1960-1970: evaluation of diagnostic. Laboratory data. Cornell Vet., v.63, p.291-316, 1973. 
10-JERRET. I.V.; MOCRIST. S.; WADDINGTON, J.; BROWNING, J.W. Diagnosis studies of fetus, placenta and maternal blood from 265 bovine abortions. Cornell. Vet., v.74, p.8-20, 1984.

11-JORDAO, L.P. Diagnóstico das causas de aborto bovino. Rev. Criadores, v.121, p.81-90, 1986.

12-KIRKBRIDE, C.A.; BICKNELL, E.J.; REED, D.E.; ROBL, M.G.; KNUDTSON, W.V.; WOHLGEMUTH, K. A diagnostic survey of bovine abortion and stillbirth in the Northern PlainsStates. J. Amer. Vet. Med. Ass., v.162, p.556-60, 1973.

13-PENNER, J.L. The genus Campylobacter: a decade of progress. Clin. Microblol. Rev., v.1, p.157-72, 1988.
14-PRESCOTT, J. Treatment of leptospirosis. Cornell Vet., v.81, p.711. 1991.

15-SUGIMURA, T.; TANAKA, J.; KITA, E.; NAKAHARA. $T$. Isolation of bacterias and virus from aborted bovine fetuses. Nat. Inst. AnIm. Health Quart., v.14, p.42-7, 1974.

16-VANDAMME, P.; DEL LEY, J. Proposal for a new family, Campylobacteraceac. Int. J. Syst. Bacteriol., v.41, p.451-5, 1991.

Recebido para publicação em 05/01/93 Aprovado para publicaçăo em 02/07/93 
A - Brucella abortus

B - Leptospira sp

C. - Staphylococcus aureus

D - Campylobacter fetus

E - Streptococcus Beta hemolítico

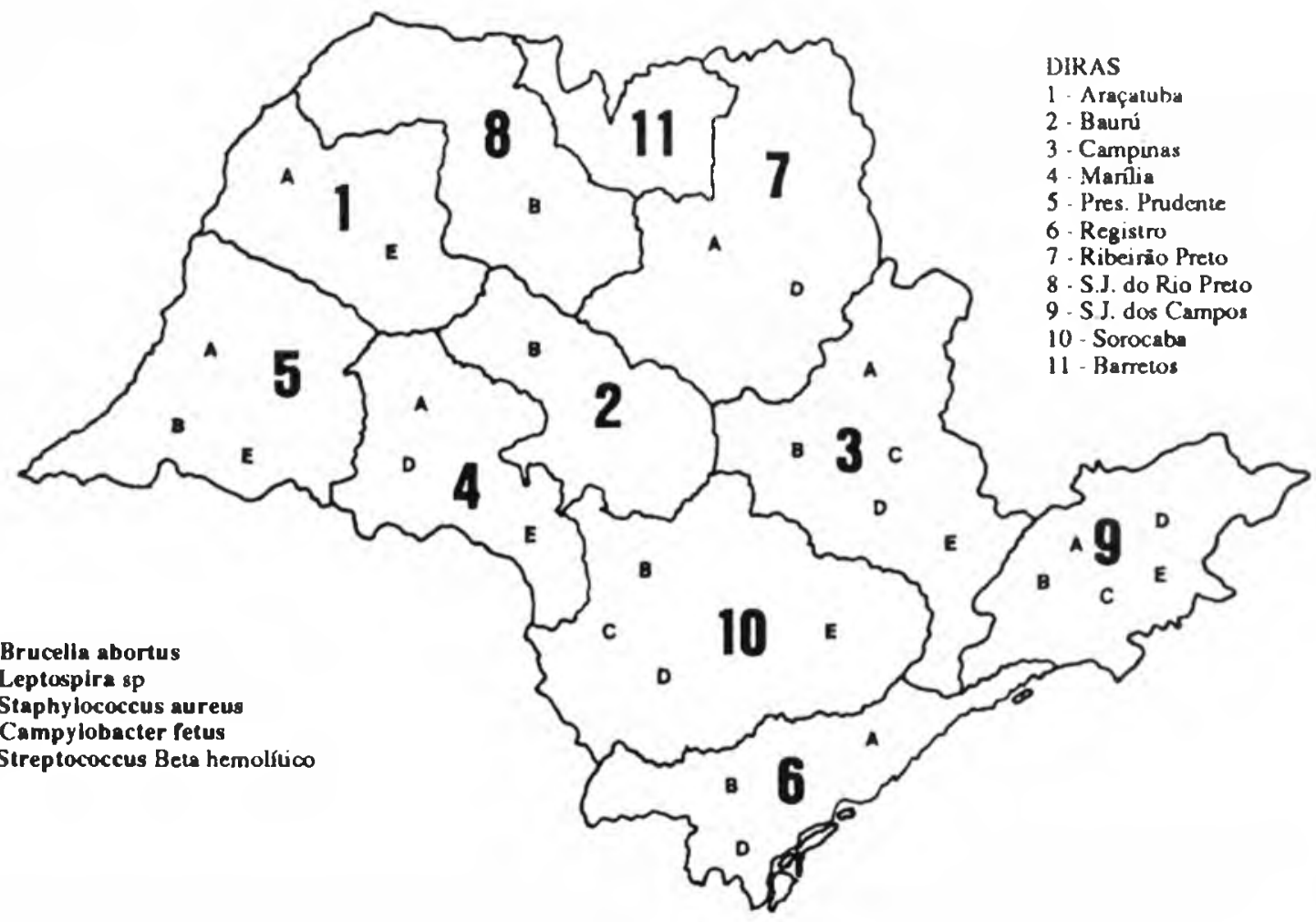

FIGURA 1

Distribuiçăo de agentes bacceranos isolados de fetos bovinos no Estado de Sżo Paulo, durante 1985-1992. 